\title{
Group A rotaviruses in children with gastroenteritis in a Canadian pediatric hospital: The prevaccine era
}

\author{
Estelle Chetrit MDCM ${ }^{1}$, Yvan L'Homme $\mathrm{PhD}^{2}$, Jagdip Singh Sohal PhD ${ }^{2}$, Caroline Quach MD MSc ${ }^{1,3}$
}

E Chetrit, Y L'Homme, JS Sohal, C Quach. Group A rotaviruses in children with gastroenteritis in a Canadian pediatric hospital: The prevaccine era. Can J Infect Dis Med Microbiol 2013;24(1):e1-e6.

BACKGROUND: A publicly funded, group A rotavirus (RVA) vaccination program was implemented in Quebec in November 2011.

OBJECTIVES: To evaluate trends in RVA infections and describe circulating genotypes before the implementation of a publicly funded vaccination program.

METHODS: The Montreal Children's Hospital (Montreal, Quebec) virology laboratory database was reviewed for RVA ELISA performed between July 2006 and June 2011. A five-week moving average was used to follow the proportion of positive RVA ELISA test results. A season was defined as starting with the first two and ending with the final two consecutive weeks in which the percentage of specimens testing positive for RVA was $\geq 10 \%$. Duplicate tests were excluded. A random sample of 39 RVA-positive fecal samples from the final season (2010/2011) was genetically characterized: VP4, VP6, VP7 and NSP4 gene segments were genotyped using sequence analysis.

RESULTS: Of the 3403 nonduplicate tests, 433 were RVA positive: $15.1 \%$ (2006/2007) to $9.3 \%$ (2010/2011) of the samples were positive during the study period, with a proportionally larger decrease in the percentage of positive tests compared with the decrease in the number of tests performed. The most common RVA strain types detected were G9P[8]I1 $(n=19)$ and G1P[8]I1 ( $n=14)$, followed by G2P[4]I2 ( $n=4)$, G3P[6]I1 ( $n=1)$ and G4P[8]I2 ( $n=1)$. Mixed RVA infection was observed in two samples.

CONCLUSION: Before the implementation of the vaccination program, the proportion of positive RVA tests had already begun to steadily decline. The present study was the first to report the genetic makeup of human RVA collected from a Canadian hospital based on the genotyping of four gene segments. The present study provided a baseline with which to monitor the impact of the universal vaccination program.

Key Words: Epidemiology; Genotyping; Rotavirus; Sequencing

$\mathrm{G}$ roup A rotavirus (RVA) infection is the leading cause of severe Jastroenteritis (GE) in young children and the most common pathogen identified in Canadian children who seek health care for acute GE (1). The cumulative risk of hospitalization for RVA GE in the first five years of life ranges between one in 45 and one in 106 (2-4), and this risk increases to one in 25 when hospital stays $<24 \mathrm{~h}$ are included (5). This risk translates into 13,600 Canadian children younger than five years of age hospitalized each year due to RVA GE (6). Health care-associated (HA) RVA infections add to the burden of community-acquired illness, with an average incidence of 0.8 per 1000 patient days in children younger than five years of age (7). Immunization is effective for preventing RVA infection and decreasing RVA-associated health care use (8-18).

RVAs are genetically highly diverse due to evolutionary mechanisms such as point mutations, recombination, and segment reassortment events between homologous and heterologous strains $(19,20)$.

\author{
Les rotavirus du groupe A chez les enfants atteints \\ de gastroentérite dans un hôpital pédiatrique \\ canadien : l'époque qui a précédé le vaccin
}

HISTORIQUE : En novembre 2011, le Québec a commencé à financer un programme de vaccination contre le rotavirus du groupe A (RVA). OBJECTIFS : Évaluer les tendances des infections par le RVA et décrire les génotypes en circulation avant la mise en œuvre d'un programme de vaccination financé par le gouvernement.

MÉTHODOLOGIE : Les chercheurs ont analysé la base de données du laboratoire de virologie de L'Hôpital de Montréal pour enfants de Montréal, au Québec, pour en extraire les tests ELISA du RVA effectués entre juillet 2006 et juin 2011. Ils ont utilisé une moyenne mobile de cinq semaines pour suivre la proportion de résultats de tests ELISA positifs au RVA. Ils ont défini une saison comme commençant avec les deux premières semaines consécutives au cours desquelles au moins $10 \%$ des échantillons étaient positifs au RVA et se terminant avec les deux dernières semaines présentant ces caractéristiques. Ils ont exclu les tests dédoublés. Ils ont procédé à la caractérisation génétique d'un échantillon aléatoire de 39 coprocultures positives au RVA de la dernière saison (2010-2011) : ils ont génotypé les segments de gène VP4, VP6, VP7 et NSP4 au moyen de l'analyse séquentielle.

RÉSULTATS : Sur les 3403 tests non dédoublés, 433 étaient positifs au RVA : de 15,1\% (2006-2007) à 9,3\% (2010-2011) des échantillons étaient positifs pendant la période de l'étude, la diminution étant proportionnellement plus importante en matière de pourcentage de tests positifs que de nombre de tests effectués. Les types de souches de RVA les plus décelés étaient le G9P[8]I1 ( $n=19)$ et le G1P[8]I1 ( $n=14)$, suivis du G2P[4]I2 ( $n=4)$, du G3P[6]I1 $(n=1)$ et du G4P[8]I2 ( $n=1)$. Dans deux échantillons, les chercheurs ont observé une infection à RVA mixte.

CONCLUSION : Avant la mise en œuvre du programme de vaccination, la proportion de tests positifs au RVA avait déjà commencé à subir une baisse constante. La présente étude est la première à avoir rendu compte de la constitution génétique du RVA humain prélevé dans un hôpital canadien d'après le génotypage de quatre segments de gène. Elle fournit un point de départ pour surveiller les répercussions du programme de vaccination universelle.

RVA forms an individual genus within the Reoviridae family, the genome of which consists of 11 double-stranded RNA segments encoding six structural (VP1 to VP4, VP6 and VP7) and six nonstructural proteins (NSP1 to NSP6) (19). RVAs are classified antigenically and genetically according to a binomial system based on the main antigenic determinants; the outer capsid proteins VP7 and VP4, which specify the $G$ and $P$ serotypes/genotypes, respectively (19-21). To date, $27 \mathrm{G}$ and $35 \mathrm{P}$ genotypes have been documented $(21,22)$. Recently, a new RVA classification system has been proposed in which all 11 segments are considered $(22,23)$. Following this classification system, the VP6 gene segment (which encodes a protein that constitutes the inner capsid layer of the virion) and the NSP4 gene segment (which encodes a protein involved in viral replication and also possesses enterotoxic activity) have, to date, been classified in 15 I (VP6) and 12 E (NSP4) genotypes $(21,22)$. The recent introduction of human RVA vaccines in different countries has raised questions of whether vaccination

${ }_{1}^{1}$ Infectious Disease Division, Department of Pediatrics and Medical Microbiology, The Montreal Children's Hospital, McGill University, Montreal;

${ }^{2}$ Canadian Food Inspection Agency, St Hyacinthe Laboratory, St Hyacinthe; ${ }^{3}$ Department of Epidemiology and Biostatistics, McGill

University, Montreal, Quebec

Correspondence: Dr Caroline Quach, The Montreal Children's Hospital of the McGill Universtiy Health Centre, C1242 - 2300 Tupper Street,

Montreal, Quebec H3H 1P3. Telephone 514-412-4485, fax 514-412-4494, e-mail caroline.quach@mcgill.ca 
could drive the selection of rare or atypical strains, including animalhuman reassortant viruses not currently included in vaccine formulations. Surveillance studies conducted in several countries to monitor the effect of vaccination on strain diversity have revealed that the most common circulating human genotypes include G1, G2, G3, G4 and $\mathrm{G} 9$ in combination with $\mathrm{P}[8]$ and $\mathrm{P}[4]$ (24-26). In addition, a small percentage of rare genotypes, including reassortant strains, and potential zoonotic and human-animal hybrid strains, have also been detected in various countries (24-26).

Two RVA vaccines are currently approved and available in Canada: a pentavalent vaccine containing a combination of five reassortant human-bovine viruses (G1, G2, G3, G4 and P[8]) (RotaTeq [RV5], Merck, USA) and a monovalent vaccine containing a live-attenuated strain of P[8]G1 (Rotarix [RV1], GlaxoSmithKline, United Kingdom). Based on cost-effectiveness analyses, Quebec used RV1 for their publicly funded program, which began November 1, 2011 (27).

Until recently, in Canada, in the absence of a publicly funded RVA vaccination program, vaccine coverage remained low (13\% of children one year of age had received at least a single dose) $(28,29)$. The objectives of the present study were to evaluate trends in RVA infections from 2006 to 2011 and to gather information regarding RVA genotypes circulating in Montreal, Quebec, before the implementation of the publicly funded vaccination program. Therefore, complete VP7, VP6, NSP4 and partial VP4 gene segments were genotyped using sequence analysis.

\section{METHODS}

Study setting and design

The Montreal Children's Hospital (MCH, Montreal, Quebec) is a 140bed teaching hospital with $>75,000$ annual visits to its emergency department, of which $>3000$ are for GE. RVA testing is performed, using a commercially available ELISA kit according to the manufacturer's instructions (until 2008, Pathfinder Rotavirus EIA Kit, BioRad Laboratories Inc, USA; after 2009, Premier Rotaclone, Meridian Diagnostics, USA). The MCH virology laboratory does not have any restrictions with regard to the seasonality of RVA testing. To determine whether there were any trends in the burden of RVA infections at the $\mathrm{MCH}$, ELISA testing data from the MCH laboratory from July 2006 to June 2011 were retrospectively reviewed. Using the laboratory information system, all RVA tests that were performed with medical record numbers to enable removal of duplicates were extracted. Seasons were defined from July through June of the following year and were compared using aggregated weekly data to determine trends in RVA infectivity, season peak and timing.

\section{Definitions}

A season was defined to start with the first two consecutive weeks and end with the final two consecutive weeks in which the percentage of specimens testing positive for RVA was $\geq 10 \%$. The peak of the season was defined as the week with the largest percentage of specimens that tested positive for RVA. Duplicate tests, defined as tests ordered within $48 \mathrm{~h}$ of a previous test with the same result, were excluded. The total number of tests, the total number of positive tests and the proportion of positive tests from July 2006 to June 2011 were aggregated weekly and compared from one season to the next.

\section{Analysis \\ Due to the small size and the intrinsic variability of the sample, a five- week unweighted moving average was used to interpret the data. The total number of RVA tests and the proportion of positive RVA tests were followed over time. Data from the final two weeks of June 2006 through the first two weeks of July 2011 were collected and included in the analysis to enable the use of the moving average.}

\section{Genotyping of RVA strains}

A total of 39 anonymized, randomly selected, RVA-positive fecal samples from RVA-positive specimens collected during the final season (2010/2011) were further genotyped. All samples were collected from patients referred to or admitted to the $\mathrm{MCH}$, or from specimens sent to the $\mathrm{MCH}$ laboratory. Fecal samples were stored at $-70^{\circ} \mathrm{C}$. Twenty per cent fecal suspensions were prepared in Eagle minimum essential medium (Invitrogen, Canada) and filtered twice using $0.45 \mu \mathrm{m}$ and $0.22 \mu \mathrm{m}$ filters (Millipore, USA) and stored at $-70^{\circ} \mathrm{C}$. Viral RNA was extracted using a commercially available viral RNA mini kit (Qiagen, Canada) following the manufacturer's protocol.

RVA screening by reverse transcription polymerase chain reaction (RT-PCR): All samples were screened for RVA using RT-PCR performed with a commercially available RT-PCR kit (One-Step RT-PCR, Qiagen) using primers Beg9 (5'-GGCTTTAAAAGAGAGAATTTCCGTCTGG-3') and End9 (5'-GGTCACATCATACAATTCTAATCTAAG-3') (30), which targeted the complete VP7 gene segment (1062 nucleotides); primers Con3 (5'-TGGCTTCGCTCATTATAGACA-3') and Con2 (5'-ATTTCGGACCATTTATAACC-3') (31), which targeted the variable VP8* section of the VP4 gene segment (876 nucleotides); and primers GENVP6F (5'-GGCTTTWAAACGAAGTCTTC-3') and GENVP6R (5'-GGTCACATCCTCTCACT-3') (22), which targeted the complete VP6 gene segment (1356 nucleotides). A total of five selected samples (one of each VP4/VP7 genotype combination) were also screened for the NSP4 segment using the GENNSP4F (5'-GGCTTTTAAAAGTTCTGTTCC-3') and GEN-NSP4R (5'-GGWYACRYTAAGACCRTTCC-3') primers (22), which targeted the complete segment (751 nucleotides). Viral RNA was heated for 3 min at $97^{\circ} \mathrm{C}$ to denature the double-stranded RVA RNA segments and were quickly placed back on ice. RT-PCR was performed as described by the manufacturer using $0.6 \mu \mathrm{M}$ of each primer in a $25 \mu \mathrm{L}$ reaction volume. RT was performed at $50^{\circ} \mathrm{C}$ for $30 \mathrm{~min}$ followed by $15 \mathrm{~min}$ at $95^{\circ} \mathrm{C}$. DNA amplification was performed for 40 cycles, consisting of $60 \mathrm{~s}$ at $94^{\circ} \mathrm{C}, 30 \mathrm{~s}$ at $45^{\circ} \mathrm{C}$ and $120 \mathrm{~s}$ at $72^{\circ} \mathrm{C}$. Amplification products were seperated on $1 \%$ agarose gels containing SYBR Safe DNA Gel Stain (Invitrogen, USA) and visualized using ultraviolet light. Amplicons of the expected molecular weight were extracted from the gel and purified using a commercially available kit (Qiaquick Gel Extraction Kit, Qiagen). Resulting RT-PCR amplicons were subjected to sequence analysis using the respective PCR primers and a commercially available kit (BigDye Terminator v3.1 Cycle Sequencing Kit, Invitrogen) using a 3730xl instrument (Applied Biosystems, USA). Sequences with evidence of mixed populations of amplicons were cloned using a commercially available kit (pGEM-t Easy cloning kit, Promega, Canada); six to 12 clones were sequenced as described above. Sequences were analyzed and edited using the GENEIOUS software version 5.4 (Biomatters Ltd, New Zealand). Sequences were compared with datasets using the Basic Local Alignment of Sequences Tool (BLAST; www.ncbi.nlm.nih.gov/) with default settings and the RotaC2.0 automated genotyping tool for RVA (32) to confirm identities and genotyping. Subsequent detailed phylogenetic analyses were conducted using ClustalW alignment and the maximum composite likelihood evolutionary model in MEGA version 5.0 (33), excluding all missing and ambiguous sites. Genbank accession numbers of segments characterized in the present study are JX029850 to JX029860 (VP7), JX029837 to JX029842 (VP4), JX029843 to JX029849 (VP6) and JX029831 to JX029836 (NSP4).

\section{RESULTS}

Of the 3585 RVA detection tests performed between July 2006 and June 2011, 182 were duplicates. Of the remaining 3403 tests, 433 were positive according to ELISA (12.7\%). The 2006/2007, 2007/2008 and 2008/2009 seasons demonstrated bimodal distributions with staggered onset and similar peaks (Figure 1). During the 2009/2010 and 2010/2011 seasons, the pattern of RVA positivity changed. The 2009/2010 season had a trimodal distribution, whereas the 2010/2011 season had a unimodal distribution (Figure 1).

The number of unique detection tests performed during the 2006/2007, 2007/2008, 2008/2009, 2009/2010 and 2010/2011 seasons were $767,738,713,607$ and 578, respectively (of a total of 3403 tests 


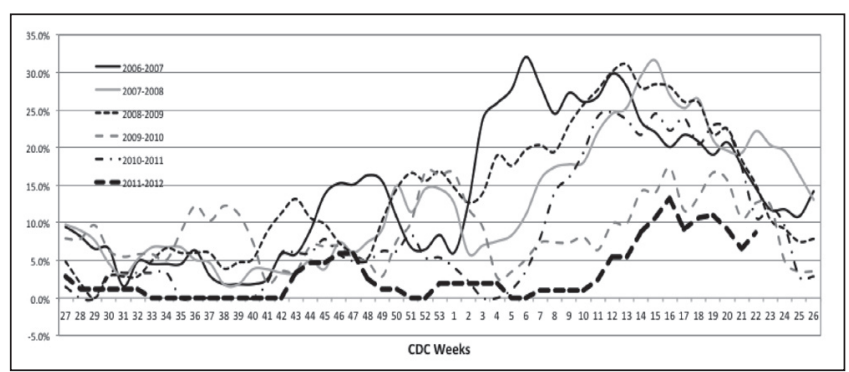

Figure 1) A superimposed five-week unweighted moving average of the percentage of positive group A rotavirus detection tests for the 2006/2007 to 2010/2011 seasons. CDC Centers for Disease Control and Prevention

TABLE 1

Group A rotavirus (RVA) specimens tested, relative to the 2006/2007 season

\begin{tabular}{lcccc}
\hline & Unique tests & RVA+, & \multicolumn{2}{c}{ Decrease from 2006/2007, \% } \\
\cline { 4 - 5 } Season & performed, $\mathbf{n}$ & $\mathbf{n}(\%)$ & RVA+ & Tests performed \\
\hline $2006 / 2007$ & 767 & $116(15.1)$ & Reference & Reference \\
$2007 / 2008$ & 738 & $103(14.0)$ & 7.7 & 3.8 \\
$2008 / 2009$ & 713 & $105(14.7)$ & 2.6 & 7.0 \\
$2009 / 2010$ & $607^{*}$ & $55(9.1)$ & 40.1 & 20.9 \\
$2010 / 2011$ & $578^{*}$ & $54(9.3)$ & 38.2 & 24.6 \\
Total & 3403 & $433(12.7)$ & & \\
\hline
\end{tabular}

${ }^{*} P<0.001$ compared with 2006/2007 and 2008/2009. + Positivity

performed between July 2006 and June 2011), yielding an overall decrease of $24.6 \%$ between the 2006/2007 and 2010/2011 seasons. The number of RVA-positive tests and the percentage of positive tests per season are reported in Table 1, with a total of 433 RVA-positive tests and a mean positivity of $12.7 \%$ over the five seasons. Compared with the 2006/2007 season, the yearly decrease in the percentage of RVA-positive ELISA tests was statistically significant for 2009/2010 and 2010/2011 ( $\mathrm{P} \leq 0.001)$. Overall, there was a proportionately larger decrease in the percentage of specimens testing positive for RVA compared with the decrease in total RVA tests performed.

RVA genotypes detected

A total of 39 RVA strains from the $\mathrm{MCH}$ collected during the 2010/2011 season were successfully G (VP7), P (VP4) and I (VP6) genotyped using sequence analysis with common primers (Figure 2). In addition, selected strains representing five different $\mathrm{G} / \mathrm{P}$ combinations were also E (NSP4) typed. The most common RVA strain types detected were G9P[8]I1 $(n=19)$ and G1P[8]I1 $(n=14)$, followed by G2P[4]I2 $(n=4)$, G3P[6]I1 $(n=1)$ and G4P[8]I2 $(n=1)$. A total of 11 VP7 sequences representing five different $G$ genotypes (G1, G2, G3, G4 and G9) were selected as representative strains of specific lineages or sublineages and were used to build a phylogenetic tree (Figure 3A). G1 sequences were found to be heterogeneous and clustered in two distinct lineages, G1-I and G1-II. Moreover, G1-I sequences were found to be clustered within two sublineages, 1a and 1d. G9 sequences were found to be less heterogeneous because they all clustered in a single lineage, III-d. G2 strains were found to be clustered tightly in lineage II. Finally, G3 and G4 strains clustered in lineage I and sublineage $\mathrm{Ib}$, respectively. The predominant $\mathrm{P}$ type among circulating strains during the time period of the present study was $P[8](n=34)$ in association with G1, G4 and G9 types. Additional P types detected were P[4] in association with $\mathrm{G} 2$ type and a single $\mathrm{P}[6]$ in association with the G3 type. One sample was found to be a mixed infection involving a G9P[4+8]. All P[8] strains clustered in linage III (Figure 3B). P[4] and $\mathrm{P}[6]$ strains clustered in lineage $\mathrm{V}$ and sublineage Ia, respectively. The majority of strains $(n=34)$ harboured the I1 type of VP6 in association with G9P[8], G1P[8] and G4P[8] constellations (Figure 4A). G2P[4] and G3P[6] strains were found in association with the I2 type of VP6. NSP4 segment analysis was performed on five samples, which were selected based on their differing G/P genotype combinations. The E1

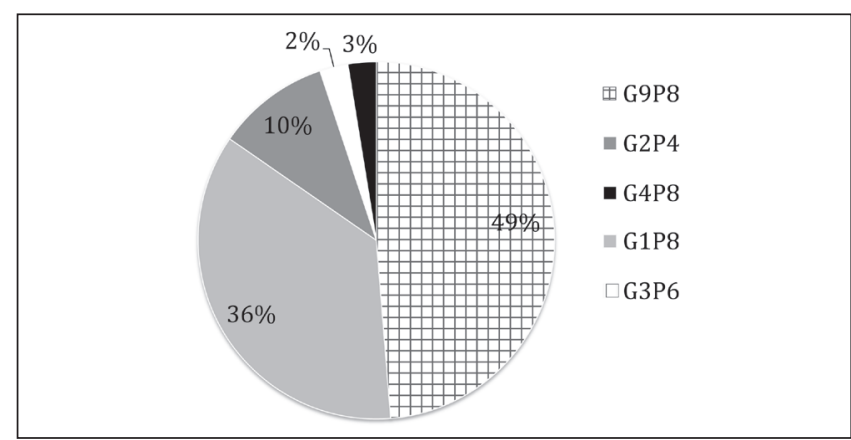

Figure 2) Circulating genotypes (2010/2011 season)

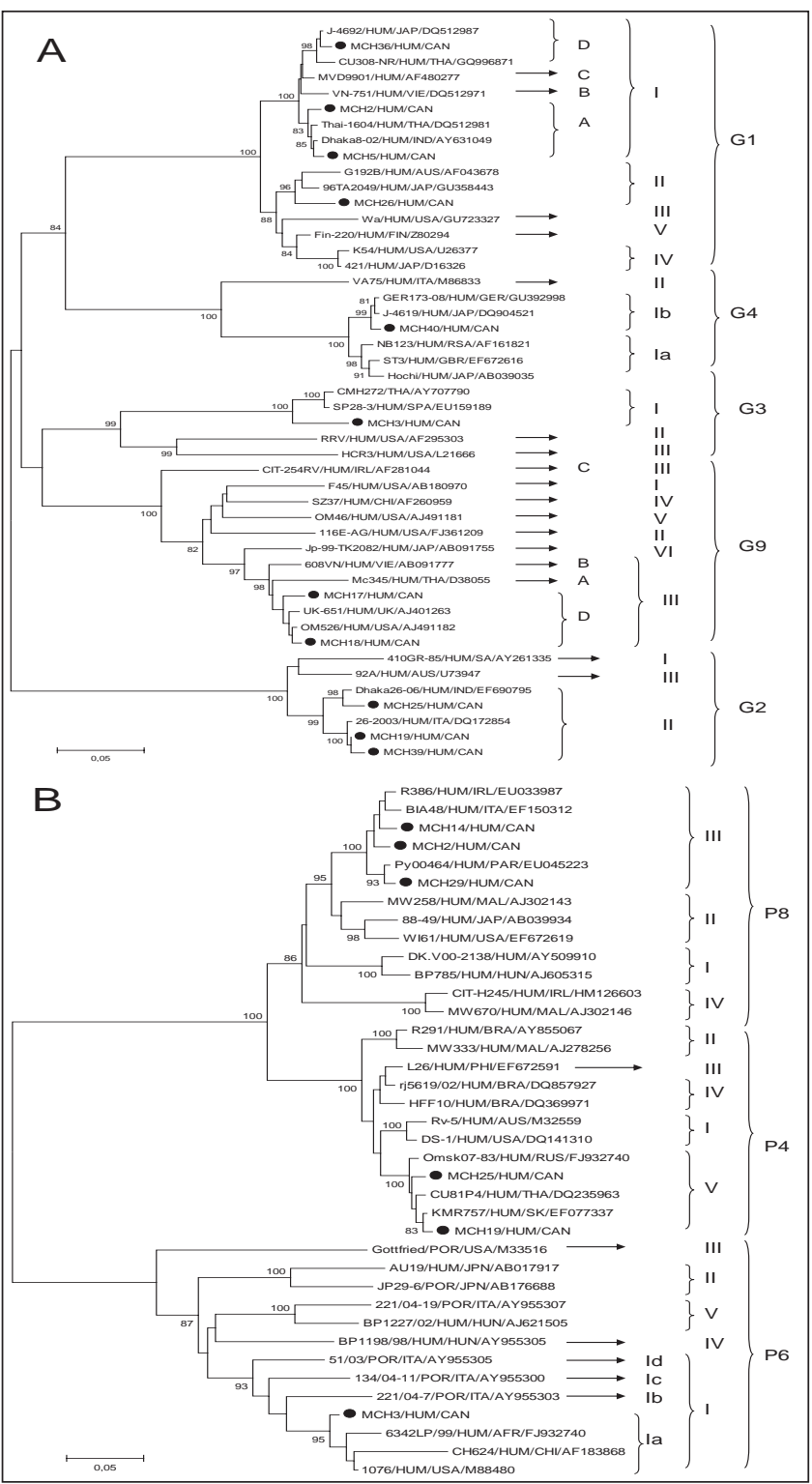

Figure 3) A Phylogenetic analysis of gene segment VP7 (G genotypes) nucleotide sequences. B Phylogenetic analysis of gene segment VP4 (P genotypes) nucleotide sequences. Alignments and tree reconstruction were performed using the Clustal W alignment program and the NJ algorithm in MEGA version 5.0 (33). Relevant $G$ and $P$ types are shown on the right side of the figures. The lineages (roman numerals) and sublineages (letters) are adapted from references 38 and 40. RVA sequences characterized in the present study are shown with a filled circle. Relevant RVA reference sequences are shown with their names, country of origin and Genbank accession number. Bootstrap values $>80 \%$ following 1000 replications are shown at the nodes 


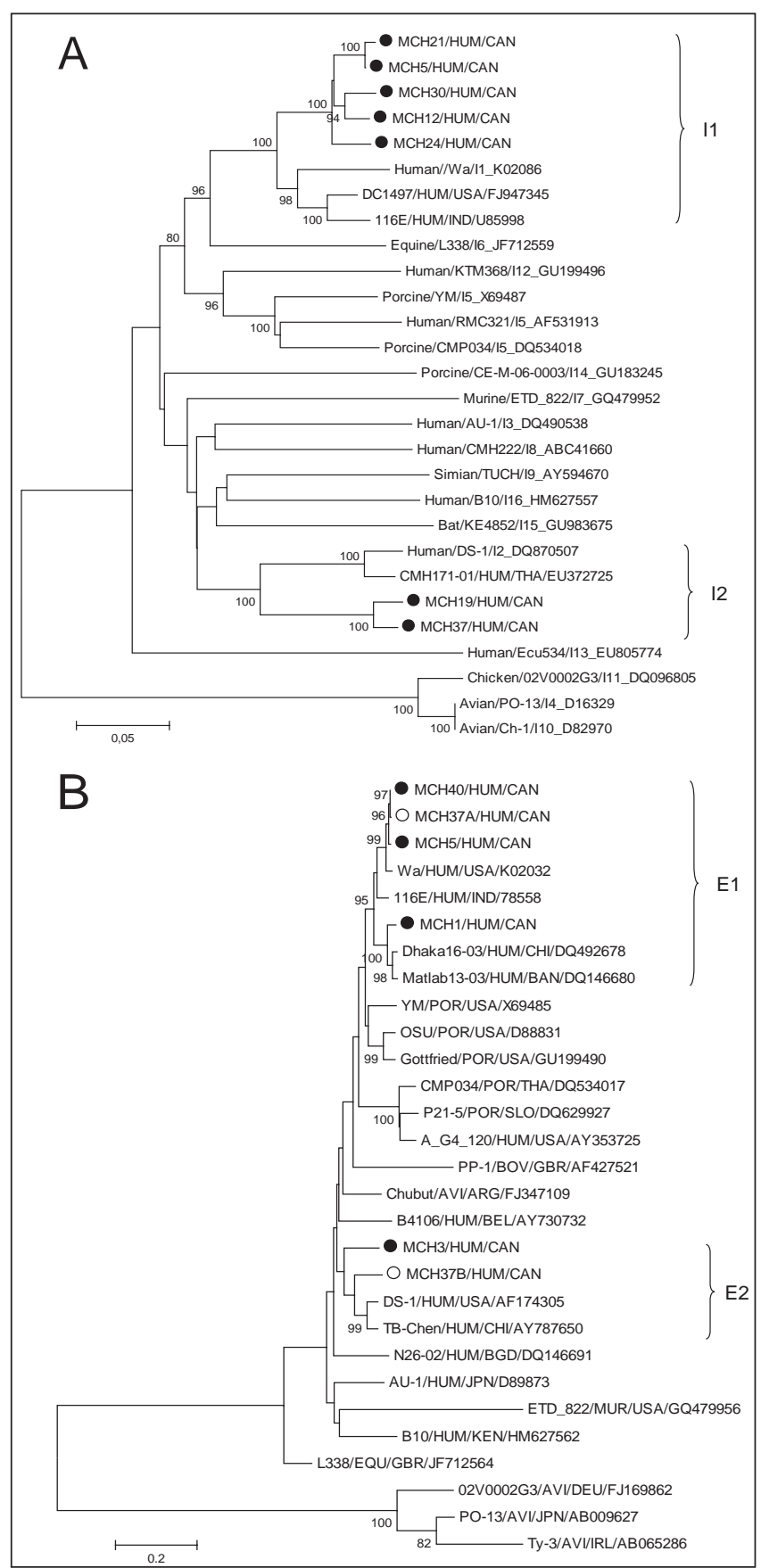

Figure 4) A Phylogenetic analysis of gene segment VP6 (I genotypes) nucleotide sequences. B Phylogenetic analysis of gene segment NSP4 (E genotypes) nucleotide sequences. Alignments and tree reconstruction were performed using the Clustal W alignment program and the NJ algorithm in MEGA version 5.0 (33). Relevant I and E types are shown on the right side of the figures and are adapted from references 22 and 38. Relevant RVA reference sequences are shown with their names, country of origin and Genbank accession number. Rotavirus sequences characterized in the present study are shown with a filled circle, except for the sequences of the mixed strains 37A-E1 and 37B-E2, which are shown with an open circle. Bootstrap values $>80 \%$ following 1000 replications are shown at the nodes

type was found to be associated with G1P[8], G9P[8], G4P[8] and mixed with an E2 genotype in a G2P[4] strain. The E2 genotype was found in the single G3P[6] strain of the present study and mixed with the E1 genotype in a G2P[4] strain (Figure 4B).

\section{DISCUSSION}

In the absence of a publicly funded RVA vaccination program and given the low vaccination coverage in Quebec $(<5 \%$ in 2008 [28] and 13\% in 2010 [29] in children younger than one year of age), the decrease in the yearly absolute number of tests performed and the proportion of positive RVA specimens, with the exception of the 2008/2009 season, suggest that there are seasonal variations in the patterns of RVA infectivity. The RVA infectivity reported for the first three yearlong seasons (2006/2007 to 2008/2009) was similar with regard to the length of season and the magnitude of the peaks. During the 2009/2010 and 2010/2011 seasons, the cumulative duration of the RVA seasons were shorter and the peak intensities were weaker than any of the peaks seen during the 2006/2007 and 2007/2008 seasons. Compared with the reference season of 2006/2007, the following seasons had a smaller proportion of positive RVA tests and a reduction in the number of RVA tests performed. Tate et al (13) found an association between the introduction of the national American RVA vaccination program and the sustained decline in positive specimens in the United States (US) over the subsequent three seasons compared with the prevaccine era. The effect was most significant during the 2009/2010 season, in which the a priori threshold of $10 \%$ RVA-positive tests for season start was never reached. The changes in the distribution, intensity and length of the 2009/2010 and 2010/2011 seasons compared with the previous three seasons in the present study, in the absence of a similar Canadian campaign, suggest that other factors may have contributed to the decline. One hypothesis is that Quebec is indirectly benefiting from the American RVA vaccination program. However, such an inference is difficult to make. One would expect herd immunity to be apparent if some proportion of the population was in contact with the immunized population, thus, preventing the spread of disease among the unimmunized. In the present case, RVA was transmitted through contact and, therefore, herd immunity based solely on the presence of high vaccination rates against RVA in the US is unlikely.

Furthermore, Tate et al (13) suggested that the proportionately greater decline in the percentage of RVA specimens testing positive compared with the decline in the number of tests performed was attributable to a decline in RVA-related health care visits in the post-vaccination era. RVA vaccine uptake in Quebec increased by more than two-fold from 2008 to 2010: $4.6 \%$ and $4.0 \%$ of children one year of age had received at least one dose and all three doses of RVA vaccine, respectively, in 2008 (28) compared with 13\% and $12.1 \%$, respectively, in 2010 (29). However, it is debatable whether this minimal vaccine coverage could have an impact similar to what was observed in the US following the implementation of their national vaccination program. The decline in positive RVA specimens in the US was observed within the first year of implementation of the vaccine program. However, vaccination coverage in the US increased rapidly, with $50 \%$ to $60 \%$ of infants younger than six years of age receiving vaccination; these proportions are much higher than what has been reported for Quebec.

The actual prevalence of RVA infection remains uncertain because it is not a reportable infectious disease. In the absence of clinical guidelines, the decision whether to test is at the discretion of the treating physician and is influenced by institutional and personal practices. For most cases of GE - even in hospitalized patients - clinicians do not perform laboratory testing, likely because RVA is believed to be a benign childhood disease and because there is no specific antiviral treatment for RVA (34). Thus, passive surveillance contributes to the hypothetical variation in the frequency of specimen testing. To be able to draw conclusions on RVA-related health care visits and on the representativeness of the RVA testing performed, active prospective surveillance is required.

During the past few decades, human RVA G and P genotypes, such as G1, G2, G3, G4 and G9 in association with P[4] and P[8], have represented the most prevalent circulating strain, with G1P[8] standing out as the most commonly identified strain in developed countries (26). Limited $G$ and $P$ typing data from Canadian centres reveal similar trends (35-37). However, although relatively few RVA G/P types, represent $>80 \%$ of the circulating strains in all of the countries studied, to 
date, an impressive diversity of strains with more than $40 \mathrm{G} / \mathrm{P}$ type combinations have been observed to cocirculate in studied populations $(25,26,38)$. Moreover, the occurrence of uncommon and potentially emerging human strains, such as G12, the existence of specific 'regional' strains and strains of potentially zoonotic origins have also been reported $(26,39,40)$. Findings from the present work reveal that all but one of the strains detected were considered to be typical or common human RVA strains (G1P[8], G9P[8], G4P[8] and G2P[4]). Furthermore, the VP6 and NSP4 typing results for these strains were in accordance with other studies and revealed typical I1 and E1 genotypes associated with G1P[8], G9P[8], G4P[8] strains and I2 and E2 genotypes associated with G2P[4] strains (41,42). On the other hand, G3P[6] strains have been detected sporadically in humans and are believed to represent human-porcine reassortant viruses $(25,40,43)$. The P[6] VP4 allele, in particular, is believed to have had a complex evolutionary history involving multiple trans-species transmission events between humans and pigs (43). The existence of circulating human-animal reassortant strains emphasizes the need for additional surveillance to monitor the existence and extent of these phenomena.

Mixed RVA infection was observed in two clinical samples in the present study. Mixed infections form the basis for reassortment events of segmented viruses, which can lead to novel combinations of segments between homologous or heterologous strains. Such atypical strains bearing new segment combinations of either human or human/animal origin, similar to influenza viruses, can generate immunological shifts and quickly spread through an immunologically naive population.

Although the number of strains genotyped in the present study was limited, it nonetheless uncovered the large diversity of RVA strains that were cocirculating during the short time period of the present study. In addition to five distinct G/P genotype combinations, the present study found notable intragenotype variability for all of the segments. Overall, these results mirror the situation found in other industrialized countries.

Based on the samples available in the present study, we found that the majority of circulating genotypes were currently covered - at least partially - by the publicly funded vaccination program that has been implemented. Overall, $36 \%$ of the strains possessed both serotype antigens that were also present in the RV1 vaccine (G1P[8]), an additional $51 \%$ of the strains also possessed the VP4 antigen that was present in the current vaccine (P[8]). However, a total of $13 \%$ of the identified strains in the present work that possessed both serotype antigens (eg, G2P[4] and G3P[6]) differed from the serotype antigens present in the Rotarix vaccine. Furthermore, the intragenotypic heterogeneity raised concerns regarding the ability of the vaccine to neutralize all circulating variants. The existence of antigenic diversity within genotypes has been suggested for both VP4 and VP7 antigens (44-46). Continued monitoring of the genetic diversity of circulating RVA strains using nucleotide sequencing is, therefore, warranted. Escape mutants of human, human/animal or strictly animal origin could emerge and subsequently spread throughout the population. RVA strain surveillance will ensure that vaccines are continuously updated and remain efficacious against the ever evolving RVA strains.

The data collected from the MCH have several limitations. First, because the present study was ecological in nature, patient demographics and clinical characteristics were not available, which precluded the the ability to perform any analyses according to age, vaccination status or comorbidities. While it has been estimated that $11 \%$ to $32 \%$ of RVA GE cases are hospital acquired in the developed world (47-51), and that $31 \%(52)$ and $59 \%$ (7) of community-acquired and HA RVA infections requiring hospitalization, respectively, have underlying comorbidities, the level of detail available in the present study was insufficient to identify community-acquired versus HA RVA infections. However, the $\mathrm{MCH}$ has been performing total hospital HA infection surveillance for the past 25 years. Our HA RVA GE incidence rate has been previously reported (53). Between 1998 and 2008, the annual incidence of HA RVA GE varied from 0.26 per 1000 patient days to 0.81 per 1000 patient days, with no trend toward a change in rate, as tested using Poisson regression. In the past three years, the incidence has been 0.46 per 1000 patient days
(2009), 0.19 per 1000 patient days (2010) and 0.10 per 1000 patient days (2011). Two small outbreaks (three patients each) occurred in 2009 in the $\mathrm{MCH}$ neonatal intensive care unit, thus, we do not believe that HA outbreaks impacted the number of tests performed.

The present study used the definitions from studies conducted by Tate et al $(13,54)$ to determine RVA season, timing and peaks. Although our data were collected from a single university-affiliated hospital, the $\mathrm{MCH}$ serves approximately $50 \%$ of the region's pediatric population, which has an annual birth cohort of 23,260 (55). Our results are not necessarily generalizable to Canada; however, given the high variability in testing practices for RVA, we opted for a design that would allow for good internal validity. The MCH algorithm has not changed in recent years and our laboratory does not restrict testing to specific patient populations or seasons, which may not be the case in other institutions, and could affect the generalizability of these findings to other institutions.

The present study provided a preimplementation picture of pediatric RVA GE in a large, urban, Canadian city and highlighted the changing epidemiology of RVA, which began before the introduction of the vaccination program. The present study was also the first to report the genetic makeup of human RVA from a Canadian hospital based on the analysis of four gene segments. Although the present study is limited to a local setting and a relatively short time span, it revealed remarkable strain heterogeneity and provided a baseline with which to monitor the epidemiology of circulating RVA strains. A nationwide network for the surveillance of gastrointestinal pathogens, with active surveillance to enable improved understanding of passively tested patients, should be created to examine rates of infectivity based on geographical distribution and to monitor the impact of the implementation of an RVA-vaccination program in Canada.

DISCLOSURES: CQ has received research funding from Merck-Frosst and from GlaxoSmithKline for work on rotavirus infections, unrelated to the current study. The other authors have no conflicts of interest to declare.

\section{REFERENCES}

1. Senecal M, Brisson M, Lebel MH, et al. Measuring the Impact of Rotavirus Acute Gastroenteritis Episodes (MIRAGE): A prospective community-based study. Can J Infect Dis Med Microbiol 2008; 19:397-404

2. Ford-Jones EL, Wang E, Petric M, Corey P, Moineddin R, Fearon M. Rotavirus-associated diarrhea in outpatient settings and child care centers. The Greater Toronto Area/Peel Region PRESI Study Group. Pediatric Rotavirus Epidemiology Study for Immunization. Arch Pediatr Adolesc Med 2000;154:586-93.

3. Buigues RP, Duval B, Rochette L, et al. Hospitalizations for diarrhea in Quebec children from 1985 to 1998: Estimates of rotavirusassociated diarrhea. Can J Infect Dis 2002;13:239-44.

4. Rivest P, Proulx M, Lonergan G, Lebel MH, Bedard L. Hospitalisations for gastroenteritis: The role of rotavirus. Vaccine 2004:22:2013-7.

5. Bernard S, Valiquette L, Cyr C, Babakissa C, Côté-Boileau T, Gagneur A. Epidemiology of rotavirus acute gastroenteritis in children in a region of Quebec, Canada (2002-2008). [Paper]. The 28th Annual Meeting of the European Society For Pediatric Infectious Diseases. Nice, May 4 to 8, 2010.

6. Gagneur A, Nowak E, Lemaitre T, et al. Impact of rotavirus vaccination on hospitalizations for rotavirus diarrhea: The IVANHOE study. Vaccine 2011;29:3753-9.

7. Verhagen P, Moore D, Manges A, Quach C. Nosocomial rotavirus gastroenteritis in a Canadian paediatric hospital: Incidence, disease burden and patients affected. J Hosp Infect 2011;79:59-63.

8. Staat MA, Payne DC, Donauer S, et al. Effectiveness of pentavalent rotavirus vaccine against severe disease. Pediatrics 2011;128:e267-e75.

9. Buttery JP, Lambert SB, Grimwood K, et al. Reduction in rotavirusassociated acute gastroenteritis following introduction of rotavirus vaccine into Australia's National Childhood vaccine schedule. Pediatr Infect Dis J 2011;30(1 Suppl):S25-9. 
10. Wang FT, Mast TC, Glass RJ, Loughlin J, Seeger JD. Effectiveness of the pentavalent rotavirus vaccine in preventing gastroenteritis in the United States. Pediatrics 2010;125:e208-13.

11. Tate JE, Cortese MM, Payne DC, et al. Uptake, impact, and effectiveness of rotavirus vaccination in the United States: Review of the first 3 years of postlicensure data. Pediatr Infect Dis J 2011;30(1 Suppl):S56-60.

12. Lambert SB, Faux CE, Hall L, et al. Early evidence for direct and indirect effects of the infant rotavirus vaccine program in Queensland. Med J Aust 2009;191:157-60.

13. Tate JE, Mutuc JD, Panozzo CA, et al. Sustained decline in rotavirus detections in the United States following the introduction of rotavirus vaccine in 2006. Pediatr Infect Dis J 2011;30(1 Suppl):S30-4.

14. Boom JA, Tate JE, Sahni LC, et al. Effectiveness of pentavalent rotavirus vaccine in a large urban population in the United States. Pediatrics 2010;125:e199-207.

15. Clark HF, Lawley D, Mallette LA, DiNubile MJ, Hodinka RL. Decline in cases of rotavirus gastroenteritis presenting to The Children's Hospital of Philadelphia after introduction of a pentavalent rotavirus vaccine. Clin Vaccine Immunol 2009;16:382-6.

16. Correia JB, Patel MM, Nakagomi O, et al. Effectiveness of monovalent rotavirus vaccine (Rotarix) against severe diarrhea caused by serotypically unrelated G2P[4] strains in Brazil. J Infect Dis 2010;201:363-9.

17. Desai SN, Esposito DB, Shapiro ED, Dennehy PH, Vazquez M. Effectiveness of rotavirus vaccine in preventing hospitalization due to rotavirus gastroenteritis in young children in Connecticut, USA. Vaccine 2010;28:7501-6.

18. Field EJ, Vally H, Grimwood K, Lambert SB. Pentavalent rotavirus vaccine and prevention of gastroenteritis hospitalizations in Australia. Pediatrics 2010;126:e506-12.

19. Estes M, Kapikian A Rotaviruses. In: Knipe DM, Howley PM, Griffin DE, et al, eds. Fields virology, 5th edn. Philadelphia: Lippincott, Williams \& Wilkins, 2007.

20. Martella V, Banyai K, Matthijnssens J, Buonavoglia C, Ciarlet M. Zoonotic aspects of rotaviruses. Vet Microbiol 2010;140:246-55.

21. Matthijnssens J, Ciarlet M, McDonald SM, et al. Uniformity of rotavirus strain nomenclature proposed by the Rotavirus Classification Working Group (RCWG). Arch Virol 2011;156:1397-413.

22. Matthijnssens J, Ciarlet M, Heiman E, et al. Full genome-based classification of rotaviruses reveals a common origin between human Wa-Like and porcine rotavirus strains and human DS-1-like and bovine rotavirus strains. J Virol 2008;82:3204-19.

23. Matthijnssens J, Ciarlet M, Rahman M, et al. Recommendations for the classification of group A rotaviruses using all 11 genomic RNA segments. Arch Virol 2008;153:1621-9.

24. Gentsch JR, Laird AR, Bielfelt B, et al. Serotype diversity and reassortment between human and animal rotavirus strains: Implications for rotavirus vaccine programs. J Infect Dis 2005;192(Suppl 1):S146-59.

25. Iturriza-Gomara $M$, Dallman $T$, Banyai $K$, et al. Rotavirus genotypes co-circulating in Europe between 2006 and 2009 as determined by EuroRotaNet, a pan-European collaborative strain surveillance network. Epidemiol Infect 2011;139:895-909.

26. Santos N, Hoshino Y. Global distribution of rotavirus serotypes/ genotypes and its implication for the development and implementation of an effective rotavirus vaccine. Rev Med Virol 2005;15:29-56.

27. Comité sur l'immunisation du Québec C-Q, C (writer). Avis du Comité sur l'immunisation du Québec sur la vaccination contre le rotavirus: Gouvernement du Québec; 2011:20.

28. Boulianne N, Bradet R, Audet D, Deceuninck G. Enquête sur la couverture vaccinale des enfants de 1 an et 2 ans au Québec en 2008. In: travail Ddrbedlsa, ed. Québec: Institut national de santé publique du Québec, 2009:201.

29. Boulianne N, Bradet R, Audet D, Ouakki M. Enquête sur la couverture vaccinale des enfants de 1 an et 2 ans au Québec en 2010. Québec: Gouvernement du Québec; 2011:125.

30. Gouvea V, Glass RI, Woods P, et al. Polymerase chain reaction amplification and typing of rotavirus nucleic acid from stool specimens. J Clin Microbiol 1990;28:276-82.

31. Gentsch JR, Glass RI, Woods P, et al. Identification of group A rotavirus gene 4 types by polymerase chain reaction. J Clin Microbiol 1992;30:1365-73.

32. Maes P, Matthijnssens J, Rahman M, Van Ranst M. RotaC: A web-based tool for the complete genome classification of group A rotaviruses. BMC Microbiol 2009;9:238.
33. Tamura K, Peterson D, Peterson N, Stecher G, Nei M, Kumar S. MEGA5: Molecular evolutionary genetics analysis using maximum likelihood, evolutionary distance, and maximum parsimony methods. Mol Biol Evol 2011;28:2731-9.

34. Dube E, Gilca V, Sauvageau C, et al. Canadian paediatricians' opinions on rotavirus vaccination. Vaccine 2011;29:3177-82.

35. Kostouros E, Siu K, Ford-Jones EL, Petric M, Tellier R. Molecular characterization of rotavirus strains from children in Toronto, Canada. J Clin Virol 2003;28:77-84.

36. Pang XL, Lee B, Boroumand N, Leblanc B, Preiksaitis JK, Yu Ip CC. Increased detection of rotavirus using a real time reverse transcription-polymerase chain reaction (RT-PCR) assay in stool specimens from children with diarrhea. J Med Virol 2004;72:496-501.

37. Le Saux N, Bettinger J, Dery P, et al. The hidden costs and characteristics of childhood rotavirus emergency visits in Canada. Pediatr Infect Dis J 2012;31:159-63.

38. Gentsch JR, Hull JJ, Teel EN, et al. G and P types of circulating rotavirus strains in the United States during 1996-2005: Nine years of prevaccine data. J Infect Dis 2009;200(Suppl 1):S99-S105.

39. Castello AA, Arguelles MH, Rota RP, et al. Molecular epidemiology of group A rotavirus diarrhea among children in Buenos Aires, Argentina, from 1999 to 2003 and emergence of the infrequent genotype G12. J Clin Microbiol 2006;44:2046-50.

40. Iturriza-Gomara M, Dallman T, Banyai K, et al. Rotavirus surveillance in Europe, 2005-2008: Web-enabled reporting and real-time analysis of genotyping and epidemiological data. J Infect Dis 2009;200(Suppl 1):S215-21.

41. Cashman O, Collins PJ, Lennon G, et al. Molecular characterization of group A rotaviruses detected in children with gastroenteritis in Ireland in 2006-2009. Epidemiol Infect 2012;140:247-59.

42. Banyai K, Bogdan A, Szucs G, et al. Assignment of the group A rotavirus NSP4 gene into genotypes using a hemi-nested multiplex PCR assay: A rapid and reproducible assay for strain surveillance studies. J Med Microbiol 2009;58:303-11.

43. Martella V, Banyai K, Ciarlet M, et al. Relationships among porcine and human P[6] rotaviruses: Evidence that the different human P[6] lineages have originated from multiple interspecies transmission events. Virology 2006;344:509-19.

44. Hoshino Y, Jones RW, Ross J, et al. Rotavirus serotype G9 strains belonging to VP7 gene phylogenetic sequence lineage 1 may be more suitable for serotype G9 vaccine candidates than those belonging to lineage 2 or 3. J Virol 2004;78:7795-802.

45. Jin Q, Ward RL, Knowlton DR, et al. Divergence of VP7 genes of G1 rotaviruses isolated from infants vaccinated with reassortant rhesus rotaviruses. Arch Virol 1996;141:2057-76.

46. Padilla-Noriega L, Mendez-Toss M, Menchaca G, et al. Antigenic and genomic diversity of human rotavirus VP4 in two consecutive epidemic seasons in Mexico. J Clin Microbiol 1998;36:1688-92.

47. Koch J, Wiese-Posselt M. Epidemiology of rotavirus infections in children less than 5 years of age: Germany, 2001-2008. Pediatr Infect Dis J Feb 2011;30:112-7.

48. Fischer TK, Bresee JS, Glass RI. Rotavirus vaccines and the prevention of hospital-acquired diarrhea in children. Vaccine 2004;22(Suppl 1):S49-54.

49. Johansen K, Hedlund KO, Zweygberg-Wirgart B, Bennet R. Complications attributable to rotavirus-induced diarrhoea in a Swedish paediatric population: Report from an 11-year surveillance. Scand J Infect Dis 2008;40:958-64.

50. Cunliffe NA, Booth JA, Elliot C, et al. Healthcare-associated viral gastroenteritis among children in a large pediatric hospital, United Kingdom. Emerg Infect Dis 2010;16:55-62.

51. Wildi-Runge S, Allemann S, Schaad UB, Heininger U. A 4-year study on clinical characteristics of children hospitalized with rotavirus gastroenteritis. Eur J Pediatr 2009;168:1343-8.

52. Le Saux N, Bettinger JA, Halperin SA, Vaudry W, Scheifele DW. Substantial morbidity for hospitalized children with communityacquired rotavirus infections: 2005-2007 IMPACT surveillance in Canadian hospitals. Pediatr Infect Dis J 2010;29:879-82.

53. Verhagen P, Moore D, Manges A, Quach C. Nosocomial rotavirus gastroenteritis in a Canadian paediatric hospital: Incidence, disease burden and patients affected. J Hosp Infect 2011;79:59-63.

54. Tate JE, Panozzo CA, Payne DC, et al. Decline and change in seasonality of US rotavirus activity after the introduction of rotavirus vaccine. Pediatrics 2009;124:465-71.

55. Institut de la Statistique du Québec, $2012<$ www.stat.gouv.qc.ca/ default.htm> (Accessed May 10, 2012). 


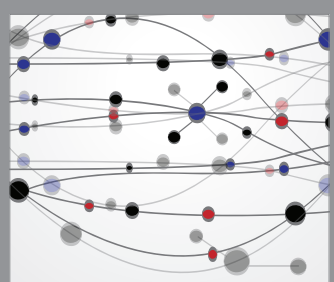

The Scientific World Journal
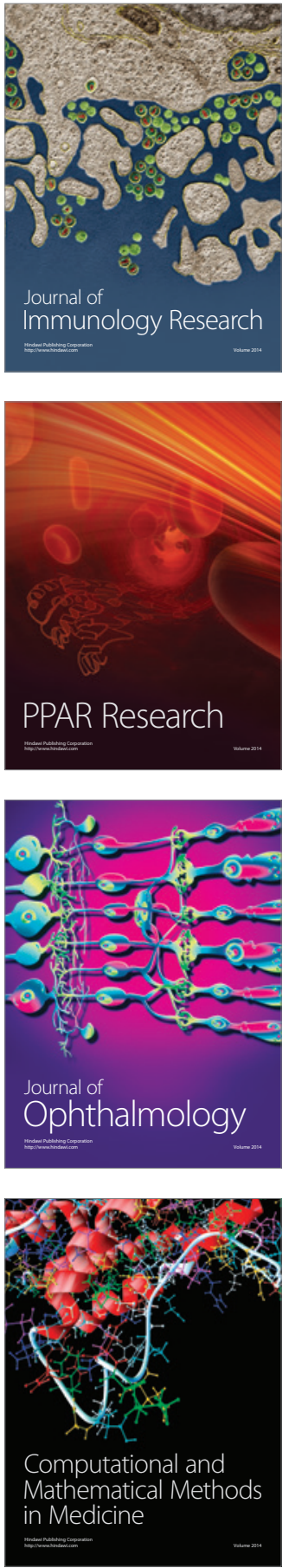

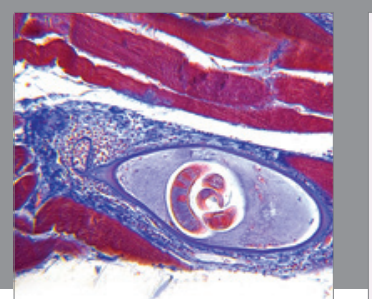

Gastroenterology Research and Practice

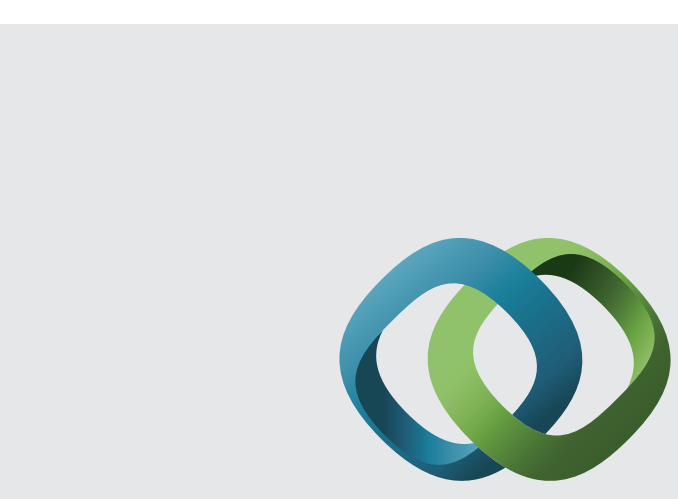

\section{Hindawi}

Submit your manuscripts at

http://www.hindawi.com
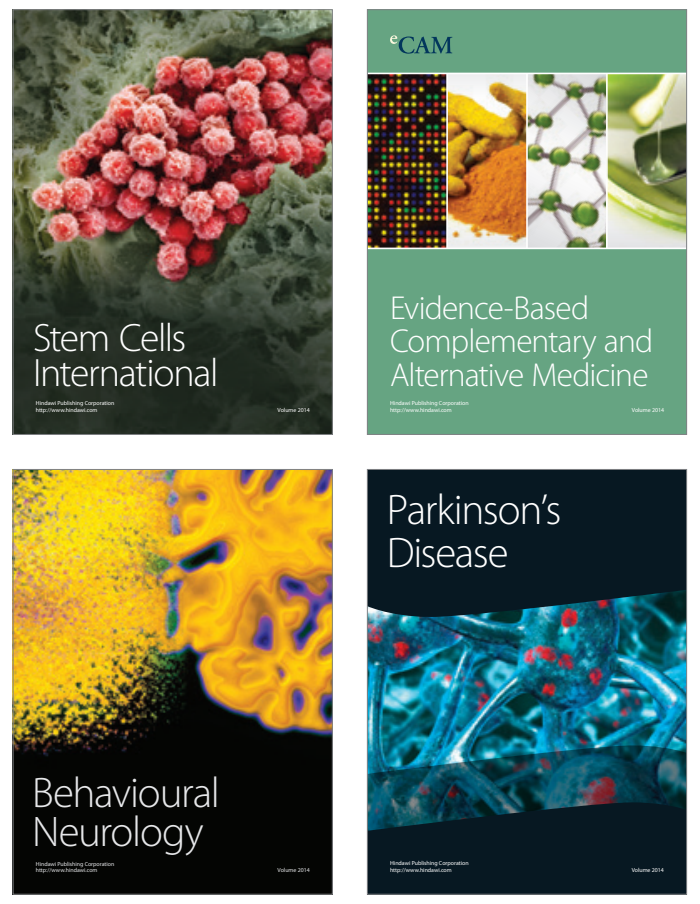
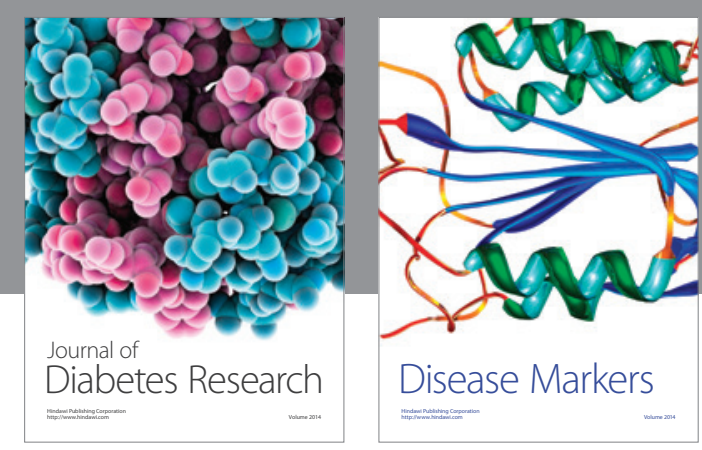

Disease Markers
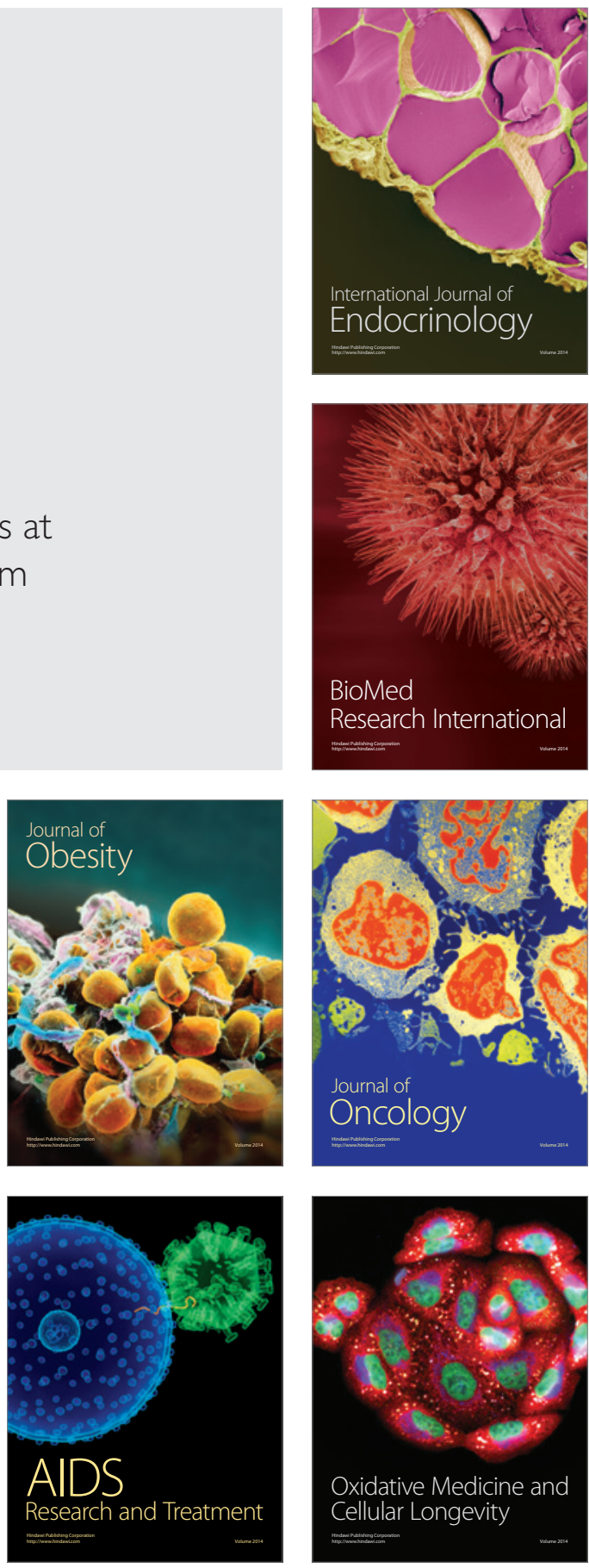